\title{
Penerapan Algoritma OTP dan Algoritma RSA CRT dalam Pengamanan Citra
}

\author{
Rani Lestari*, Relita Buaton**, Imeldawaty Gultom** \\ *Teknik Informatika,STMIK Kaputama \\ **Teknik Informatika,STMIK Kaputama
}

\section{Article Info}

Article history:

Received Juli 1 th, 2021

Revised Juli 28 th, 2021

Accepted Juli 31 th, 2021

\section{Keyword: \\ Citra}

Kriptografi

One Time Pad

RSA CRT

\begin{abstract}
ABSTRAK
Perkembangan teknologi seperti saat ini memungkinkan setiap orang untuk saling bertukar informasi tanpa ada batasan waktu dan jarak. Kemungkinan yang akan terjadi adanya kebocoran data pada saat proses pertukaran informasi yang dilakukan, oleh karena itu dalam pengiriman data khususnya citra, aspek keamanan, kerahasiaan dan efisiensi penyimpanan data sangat diperlukan. Citra ada yang bersifat rahasia ada yang tidak. Citra yang bersifat rahasia perlu mendapatkan pengamanan agar kerahasiaan gambar tidak diketahui oleh pihak yang tidak berwenang. Salah satu cara untuk melakukan pengamanan citra adalah dengan teknik kriptografi. Kriptografi citra merupakan ilmu dan seni untu menjaga keamanan citra dengan cara penyandian terhadap citra yang akan dikirim dari satu tempat ke tempat lain sehingga bentuk citra tidak dimengerti lagi maknanya. Dalam proses kriptografi banyak algoritma dan metode yang dapat digunakan untuk mengamankan suatu citra, yaitu seperti algoritma One Time Pad dan algoritma RSA CRT enkripsi citra dapat dilakukan dan semua citra berhasil dikembalikan ke bentuk citra asli. Dari penelitian ini dapat disimpulkan algoritma one-time pad dan rsa crt dapat digunakan untuk kriptografi citra dengan efektif.
\end{abstract}

\author{
Corresponding Author: \\ Nama : Rani Lestari \\ Teknik Informatika \\ STMIK Kaputama \\ Email: ranilestari678@gmail.com
}

\section{PENDAHULUAN}

Teknologi yang makin berkembang semakin memudahkan manusia untuk memenuhi kebutuhannya dalam hal komunikasi. Dahulu kala manusia harus melakukan perjalanan untuk berkomunikasi dengan orang lain di tempat yang berbeda. Namun pada masa kini manusia bisa dengan mudah berkomunikasi dengan orang lain melalui internet. Dengan hadirnya internet, informasi dapat dengan mudahnya menyebar ke seluruh penjuru dunia hanya dalam hitungan detik. Internet sebagai jalan raya informasi (the information highway) telah banyak dirasakan membawa perubahan pada banyak aspek dalam kehidupan manusia.

Pengamanan citra dengan menggunakan algoritma OTP dimana citra yang digunakan adalah citra yang berwarna (color) dan citra hitam putih (grayscale) dimana penelitian ini mempunyai kelemahan citra yang diamankan hanya berekstensi bmp saja [1]. Penelitian ini membahas tentang mengenkripsi pesan di hp android dengan menggunkan algoritma RSA CRT dimana mempunyai kelemahan proses mengenkrip pesan akan lama jika spesifikasi rendah [2]. Penyisipan pesan dan ektraksi, pesan data tersebut sulit dihitung secara manual sehingga dibutuhkan perhitungan secara komputasi melalui program namun memiliki kelemahan yaitu Untuk pembangkitan bilangan acak perlu dikembangkan dengan metode lain agar pengacakannya lebih baik tanpa harus berulang pada periode tertentu [3].

Namun internet juga merupakan salah satu jaringan publik yang tidak aman. Kegiatan-kegiatan transaksi informasi tersebut tentu saja akan menimbulkan resiko apabila informasi yang sensitif dan berharga tersebut diaksesoleh orang-orang yang tidak berhak (unauthorized persons), misalnya pesan berupa data teks atau citra yang besifat pribadi dan rahasia. Setiap orang yang mengirimkan pesan tentu berkeinginan pesan yang dikirimkan akan aman. Aman dalam artian aman dari ancaman orang yang tidak berhak. Berbagai ancaman yang mungkin terjadi antara lain tidak sampainya citra, tersadapnya citra, citra yang dimanipulasi, 
hingga penyamaran dan penyangkalan karena ada pihak yang mengirimkan citra dengan identitas orang lain. Tanpa fasilitas keamanan yang baik, sang penerima akan menerima citra tersebut tanpa mencurigai adanya perubahan yang dapat merugikan baik bagi pengirim maupun penerima. Untuk itu diperlukan sistem pengamanan yang dapat melindungi citra yang ditransmisikan melalui suatu jaringan komunikasi.

Algoritma RSA CRT merupakan algoritma kriptografi kunci publik yangterkenal aman karena sulitnya memecahkan fungsi matematis yang dipakaisebagai dasar pembuatan algoritmanya. Sedangkan algoritma OTP merupakan suatu metode yang sangat kuat, kunci yang digunakan adalah session key, dimana kunci hanya berlaku untuk satu kali proses enkripsi. Metode ini sangat baik untuk mengirim citra karena akan semakin sulit untuk mengetahui kunci yang digunakan.

Berdasarkan latar belakang di atas, maka rumusan masalah yang dibahas pada penelitian ini adalah bagaimana menerapkan teknik penyandian citra menggunakan kombinasi metode algoritma OTP dan algoritma RSA CRT dalam pengamanan citra. Tujuan Penelitian ini adalah untuk menerapkan penyandian citra menggunakan kombinasi metode algoritma OTP dan algoritma RSA CRT, sehingga dapat mengamankan citra dari pihak-pihak yang tidak bertanggung jawab.

\section{METODE PENELITIAN}

\subsection{Pengertian Kriptografi}

Kriptografi (cryptography) berasal dari bahasa Yunani yang terdiri dari dua suku kata, yaitu cryptós yang berarti rahasia dan gráphein yang berarti kata tulisan. Karena itu secara umum kriptografi diartikan sebagai tulisan rahasia.Terdapat beberapa definisi kriptografi dalam berbagai literatur. Definisi pada tahun 80-anmenyatakan kriptografi adalah ilmu dan seni untuk menjaga keamanan pesan. Kata seni dalam definisi ini berasal dari fakta sejarah bahwa pada awal sejarah kriptografi, setiap orang mempunyai cara yang unik untuk merahasiakan pesan[4].

Sedangkan definisi dalam buku-buku terbaru menyatakan kriptografi merupakan ilmu mengenai metode untuk mengirimkan pesan secara rahasia sehingga hanya penerima yang dimaksud yang dapat menghapus dan membaca pesan tersebut atau memahaminya. Pengertian lain kriptografi yaitu ilmu yang mempelajari teknik-teknik matematika yang berhubungan dengan aspek keamanan informasi seperti kerahasiaan, integritas data, serta otentikasi. Kata graphy dalam kata cryptography itu sendiri sudah menyiratkan sebuah seni.

Jadi, kriptografi adalah suatu ilmu sekaligus seni yang bertujuan untuk menjaga keamanan suatu pesan (cryptography is the art and science of keeping messages secure). Secara umum, kriptografi adalah teknik pengamanan informasi dimana informasi diubah dengan kunci tertentu melalui enkripsi sehingga menjadi informasi baru yang tidak dapat dimengerti oleh orang yang tidak berhak menerimanya, dan informasi tersebut hanya dapat di ubah kembali oleh orang yang berhak menerimanya melalui dekripsi.

\subsection{Algoritma One Time Pad}

One Time Pad merupakan salah satu algoritma yang populer dan sering digunakan dalam teknik kriptografi. OTP termasuk kelompok algoritma yang simetris dalam kriptografi dimana kunci enkripsi dan dekripsi dalam bentuk dan panjang yang sama, serta menggunakan operasi XOR. Keunggulan OTP adalah sangat sulit untuk dipecahkan tapi memiliki kekurangan dimana kunci yang digunakan kadang terlalu panjang karena harus menyesuaikan jumlah karakter yang akan dienkripsi.Dari semua metode kriptografi yang telah dirancang, OTP adalah metode yang telah terbukti benar-benar aman secara matematis.One Time Pad bisa dikatakan jika memenuhi kondisi berikut kunci harus sepanjang plainteks, kunci harus acak seluruhnya atau sepenuhnya berbeda, kunci hanya sekali digunakan setiap melakukan enkripsi, danhanya terdapat dua salinan dari kunci: satu untuk pengirim dan satu untuk penerima [1].

Algoritma One Time Pad mempunyai cara kerja dimana penerima pesanmempunya salinan kunci yang sama dan kuncitersebut hanya dipakai satu kali (one time) untuk enkripsi dan dekripsi dan setelahdigunakan maka pad (kertas blocknot)harussegera dihancurkan agar tidak bisa dipakai lagi untuk enkripsi dan dekripsi pesan yanglain.Pengirim dan penerima harus sama sama memiliki satu set materi kunci yang besar dan juga acak, selama kombinasi dari semua pesan yang pernah dikirimkan [5].

Jadi secara teori alasan OTP tidak dapat dipecahkan jika kuncinya secara sempurna diacak, dirahasiakan dan hanya dipakai sekali saja. Pada algoritma OTP mempunyai panjang kunci yang sama dengan panjang plaintext.Sehingga tidak ada kebutuhan untuk mengulang penggunaaan kunci selama proses enkripsi. Pada algoritma OTP mempunyai panjang kunci yang sama dengan panjang plaintext. Sehingga tidak ada kebutuhan untuk mengulang penggunaaan kunci selama proses enkripsi [5].

Teknik Enkripsi pada Algoritma One Time Pad

$C i=(\mathrm{Pi}+\mathrm{Ki}) \bmod 256$ 
Keterangan :

$\mathrm{Ci}=$ Cipherteks (Ciphertext)

$\mathrm{Pi}=$ Plainteks (Plaintext)

$\mathrm{Ki}=$ kunci $(\mathrm{Key})$

Teknik Dekripsi Pada Algoritma One Time Pad

$\mathrm{Ci}=(\mathrm{Pi}-\mathrm{Ki}) \bmod 256$

Keterangan :

$\mathrm{Ci}=$ Cipherteks (Ciphertext)

$\mathrm{Pi}=$ Plainteks (Plaintext)

$\mathrm{Ki}=\operatorname{kunci}(\mathrm{Key})$

\subsection{Algoritma RSA CRT (Chinese Remainder Theorem)}

Algoritma RSA with CRT adalah algoritma kunci asimetris yang diusulkan oleh Quisquarter \& Couvreur pada tahun 1982. Algoritma ini merupakan varian dari RSA berdasarkan Chinese Remainder Theorem (CRT). Pada teknik ini dua kunci rahasia yang sangat kecil $(d P, d Q)$ menghitung dari kunci rahasia asli (d), dekripsi dilakukan dengan dua buah kunci dan hasilnya digabungkan dengan bantuan dari Chinese Remainder Theorem (CRT). Algoritma kriptografi RSA with CRT dapat mempercepat kerja kunci dekripsi, untuk meningkatkan kinerja dari algoritma dekripsi dasar RSA [6].

Chinese Remainder Theorem (CRT)

Chinese Remainder Theorem adalah teorema mengenai kekongruenan lanjar dalam teori bilangan bulat yaitu aritmatika modulo. Teorema ini pertama kali di temukan oleh Sun Tze.

Misalkan $\mathrm{m}_{1}, \mathrm{~m}_{2}, \ldots, \mathrm{m}_{\mathrm{n}}$ adalah bilangan bulat positif sedemikian sehingga $\mathrm{FPB}\left(\mathrm{m}_{\mathrm{i}}, \mathrm{m}_{\mathrm{j}}\right)=1$ untuk $\mathrm{i} \neq$

$\mathrm{j}$. Maka sistem kongeruen lanjar $\mathrm{x}=\mathrm{a}_{\mathrm{k}}\left(\bmod \mathrm{m}_{\mathrm{k}}\right)$ mempunyai solusi untuk modulo $\mathrm{m}=\mathrm{m}_{1} \cdot \mathrm{m}_{2} \ldots$ . $\mathrm{m}_{\mathrm{n}}[3]$.

Pembangkit Kunci RSA-CRT

Pada Pembangkitan kunci RSA-CRT eksponen deskripsi $d$ tidak secara langsung diberikan pada kunci privat namun dapat dihitung melalui parameter $\mathrm{dP}$, dQ, dan qInv yang memiliki ukuran setengah dari panjang $n$ bit $d$. Algoritma pembangkit kunci RSA-CRT adalah sebagai berikut :

1. Pilih dua buah bilangan prima yang berbeda $p$ dan $q$

2. Hitung $\mathrm{n}=\mathrm{p} . \mathrm{q}$ (Sebaiknya $\mathrm{p} \neq \mathrm{q}$, sebab jika $\mathrm{p}=\mathrm{q}$ maka $\mathrm{n}=\mathrm{p}^{2}$ sehingga $\mathrm{p}$

dapat diperoleh dengan menarik akar pangkat dua dari $\mathrm{n}$ )

3. Hitung $\emptyset \mathrm{n}=(\mathrm{p}-1)(\mathrm{q}-1)$

4. Pilih bilangan integer $e$ dimana $1<e<\phi(N)$ dan $\operatorname{gcd}(e, \phi(N))=1$

5. Yaitu e dan $\phi(N)$ adalah relatif prima

6. Tentukan $d$ sebagai $d^{-1} \equiv e(\bmod \phi(N))$, yaitu d adalah perkalian

inverse dari $e$ (modulo $\phi(N))$

7. $\mathrm{dP}=\mathrm{d} \bmod (\mathrm{p}-1)$

8. $\mathrm{dQ}=\mathrm{d} \bmod (\mathrm{q}-1)$

9. $\mathrm{qInv}=\mathrm{q}^{-1}$ pada $\mathrm{Z}_{\mathrm{p}}$

$$
\mathrm{K}_{\text {publik }}=(\mathrm{e}, \mathrm{n}), \mathrm{K}_{\text {privat }}=(\mathrm{dP}, \mathrm{dQ}, \mathrm{qInv}, \mathrm{p}, \mathrm{q})
$$

\section{Teknik Enkripsi Pada Algoritma RSA-CRT}

Kunci publik RSA-CRT sama dengan sistem RSA yaitu (e) sehingga algoritma enkripsi tidak mengalami perubahan yaitu dengan menggunakan fungsi eksponensial modular yaitu seperti terlihat pada rumus berikut :

$\mathrm{c}_{\mathrm{i}}=\mathrm{m}_{\mathrm{i}}^{\mathrm{e}} \bmod \mathrm{n}$ 
Dimana :

- $\boldsymbol{c}_{\boldsymbol{i}}=$ chipertext

- $\boldsymbol{m}_{\boldsymbol{i}}=$ plaintext

- $\boldsymbol{e} \boldsymbol{n}=$ kunci publik

Teknik Dekripsi Pada Algoritma RSA-CRT

Pada proses dekripsi berdasarkan penyelesaian persoalan CRT, $d$ dapat dihitung kembali sehinggamemulihkan teks sandi untuk mendapatkan kembali teks asli. dengan menggunakan fungsi sebagai berikut :

$$
\begin{aligned}
& m_{1}=c_{i}{ }^{d P} \bmod \mathrm{p} \\
& m_{2}=c_{i}{ }^{d Q} \bmod \mathrm{q} \\
& h=q \ln v \cdot\left(m_{1}-m_{2}\right) \bmod p \\
& m_{1}=m_{2}+h \cdot q
\end{aligned}
$$

Dimana :

$-m_{i}=$ plaintext

$-c_{i}=$ chipertxt

$$
-d p, d Q, p, q \text {, dan qlnv = kunci privat }
$$

\section{ANALISA DAN HASIL}

\subsection{Flowchart Sistem Enkripsi OTP dan RSA CRT}

Berikut ini gambar dari flowchart sistem enkripsi OTP dan RSA CRT.

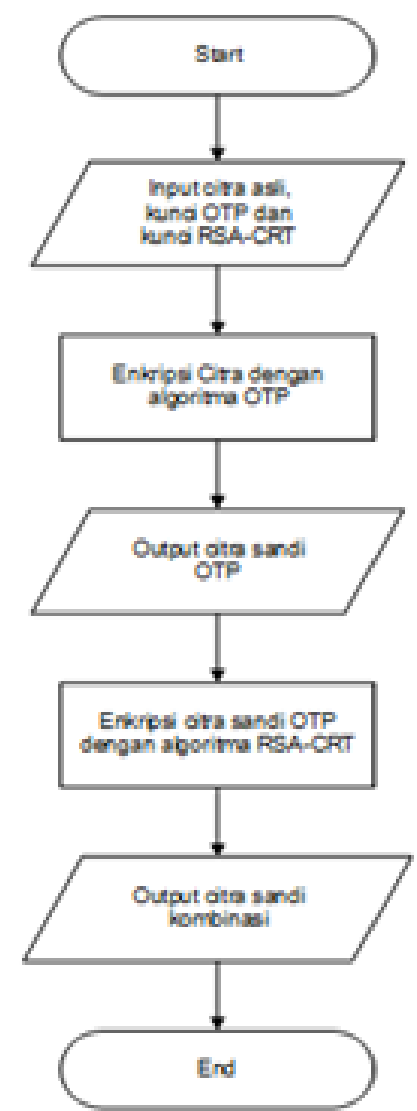

Gambar 1. Flowchart Sistem Enkripsi OTP Dan RSA CRT

\subsection{Flowchart Sistem Dekripsi OTP dan RSA CRT}


Berikut ini gambar dari flowchart sistem Dekripsi OTP dan RSA CRT.

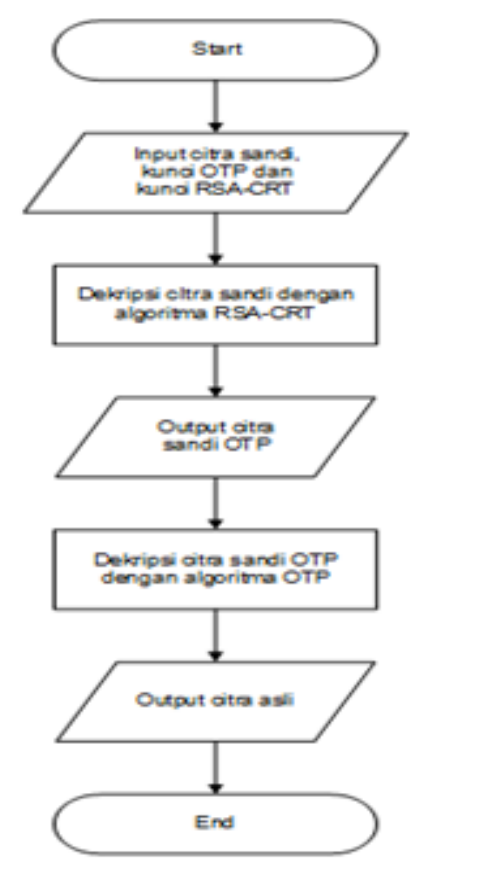

Gambar 2. Flowchart Sistem Dekripsi OTP Dan RSA CRT

\subsection{Perhitungan Enkripsi Citra Algoritma OTP}

Pada Analisis perhitungan algoritma OTP akan dimulai dengan proses mengkonversikan citra Selanjutnya analisis perhitungan algoritma OTP akan dimulai dengan proses enkripsi sehingga citra yang diinginkan diamankan menjadi tidak diketahui isinya, kemudian akan di dekripsikan kembali untuk mengembalikan citra menjadi bentuk asli, sehingga kembali dapat dilihat isinya.

Adapun gambar yang dipilih untuk mengambil nilai matriks sebagai berikut :

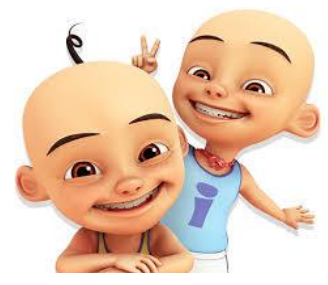

Gambar 3. Citra Format jpg

Gambar 3 merupakan gambar yang akan dilakukan enkripsi, untuk mencari nilai dari pixelnya dengan cara menggunakan software tambahan photoshop ukuran foto tersebut $3 \times 3$ 


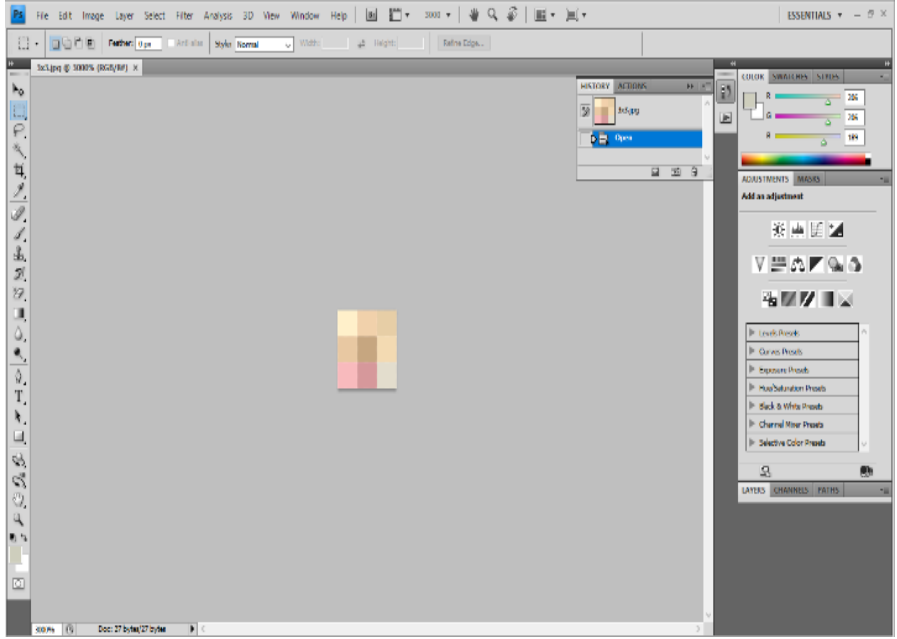

Gambar 4. Ukuran 3X3

Dari piksel-piksel citra asli dilakukan perhitungan dengan algoritma OTP dengan mengggunakan :

Kunci $=$ nH3c8

Dimana mencari Enkripsi adalah dengan rumus :

\section{$\mathrm{Ci}=(\mathrm{Pi}+\mathrm{Ki}) \bmod 256$}

Maka proses enkripsi citra dengan algoritma OTP Sebagai Berikut :

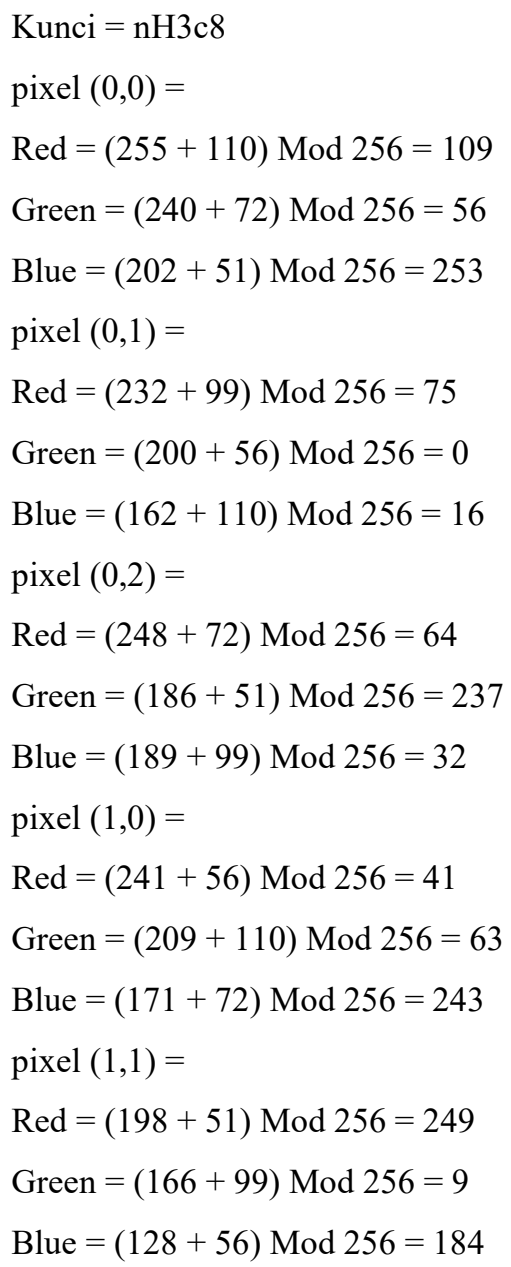




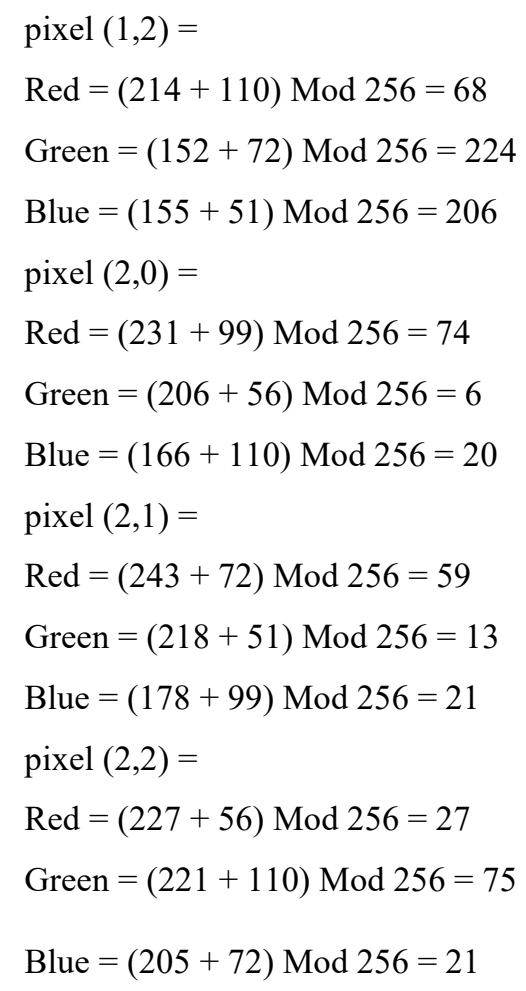

\subsection{Perhitungan Enkripsi Citra Algoritma RSA CRT}

\section{RSA-CRT:}

Dari hasil enkripsi citra dengan algoritma OTPdilakukan kembali perhitungan dengan algoritma $\mathrm{p}=29$

$\mathrm{q}=17$

$\mathrm{n}=\mathrm{p} \times \mathrm{q}=29 \times 17=493$

$\mathrm{t}(\mathrm{n})=(\mathrm{p}-1) \times(\mathrm{q}-1)=(29-1) \times(17-1)=448$

$\mathrm{dp}=71$

$\mathrm{dq}=79$

Cari nilai $\mathrm{e}=$

e $\mathrm{xd} \bmod \mathrm{t}(\mathrm{n})=1$

e $x 15 \bmod 448=1$

$239 \times 15 \bmod 448=1$

$3585 \bmod 448=1$

$1=1$

maka e $=239$

Cari nilai $\mathrm{d}=$

$\mathrm{d} \bmod (\mathrm{p}-1)=\mathrm{dp} \bmod (\mathrm{p}-1)$ dan $\mathrm{d} \bmod (\mathrm{q}-1)=\mathrm{dq} \bmod (\mathrm{q}-1)$

$\mathrm{d} \bmod (29-1)=71 \bmod (29-1) \mathrm{dan} \mathrm{d} \bmod (17-1)=79 \bmod (17-1)$

$15 \bmod (28)=71 \bmod (28)$ dan $15 \bmod (16)=79 \bmod (16)$

$15=15$ dan $15=15$

maka $\mathrm{d}=15$

Kunci Public yaitu $\quad: E=239 \quad N=493$

Kunci Private yaitu $\quad: D=15 \mathrm{~N}=493$

Dimana mencari Enkripsi adalah dengan rumus :

$$
\mathbf{C i}=\mathbf{P i}^{\mathrm{E}} \bmod \mathbf{N}
$$

Maka proses enkripsi citra dengan algoritma RSA-CRT Sebagai Berikut :

pixel $(0,0)=$

$\operatorname{Red}=\left(109^{\wedge} 239\right) \bmod 493=22$

Green $=\left(56^{\wedge} 239\right) \bmod 493=466$ 
Blue $=\left(253^{\wedge} 239\right) \bmod 493=8$

pixel $(0,1)=$

Red $=\left(75^{\wedge} 239\right) \bmod 493=447$

Green $=\left(0^{\wedge} 239\right) \bmod 493=0$

Blue $=\left(16^{\wedge} 239\right) \bmod 493=16$

pixel $(0,2)=$

Red $=(64 \wedge 239) \bmod 493=412$

Green $=\left(237^{\wedge} 239\right) \bmod 493=237$

Blue $=\left(32^{\wedge} 239\right) \bmod 493=229$

pixel $(1,0)=$

Red $=(41 \wedge 239) \bmod 493=481$

Green $=(63 \wedge 239) \bmod 493=469$

Blue $=\left(243^{\wedge} 239\right) \bmod 493=279$

pixel $(1,1)=$

$\operatorname{Red}=\left(249^{\wedge} 239\right) \bmod 493=99$

Green $=\left(9^{\wedge} 239\right) \bmod 493=444$

Blue $=(184 \wedge 239) \bmod 493=164$

pixel $(1,2)=$

Red $=(68 \wedge 239) \bmod 493=425$

Green $=\left(224^{\wedge} 239\right) \bmod 493=414$

Blue $=\left(206^{\wedge} 239\right) \bmod 493=26$

pixel $(2,0)=$

$\operatorname{Red}=(74 \wedge 239) \bmod 493=190$

Green $=\left(6^{\wedge} 239\right) \bmod 493=122$

Blue $=\left(20^{\wedge} 239\right) \bmod 493=397$

pixel $(2,1)=$

$\operatorname{Red}=(59 \wedge 239) \bmod 493=117$

Green $=\left(13^{\wedge} 239\right) \bmod 493=361$

Blue $=\left(21^{\wedge} 239\right) \bmod 493=472$

pixel $(2,2)=$

$\operatorname{Red}=(27 \wedge 239) \bmod 493=437$

Green $=\left(75^{\wedge} 239\right) \bmod 493=447$

Blue $=\left(21^{\wedge} 239\right) \bmod 493=472$

\subsection{Perhitungan Dekripsi Citra Algoritma RSA CRT}

Selanjutnya mendekripsikan dengan algoritma RSA-CRT dengan melakukan perhitungan dengan rumus sebagai berikut :

$$
\mathrm{Pi}=\mathrm{Ci}^{\mathrm{D}} \bmod \mathbf{N}
$$

Maka proses dekripsi citra dengan algoritma RSA-CRT Sebagai Berikut :

Kunci Private yaitu $\quad: \mathrm{D}=15 \mathrm{~N}=493$

pixel $(0,0)=$

$\operatorname{Red}=\left(22^{\wedge} 15\right) \bmod 493=109$

Green $=\left(466^{\wedge} 15\right) \bmod 493=56$

Blue $=\left(8^{\wedge} 15\right) \bmod 493=253$

pixel $(0,1)=$

$\operatorname{Red}=\left(447^{\wedge} 15\right) \bmod 493=75$

Green $=\left(0^{\wedge} 15\right) \bmod 493=0$

Blue $=\left(16^{\wedge} 15\right) \bmod 493=16$

pixel $(0,2)=$

$\operatorname{Red}=\left(412^{\wedge} 15\right) \bmod 493=64$ 


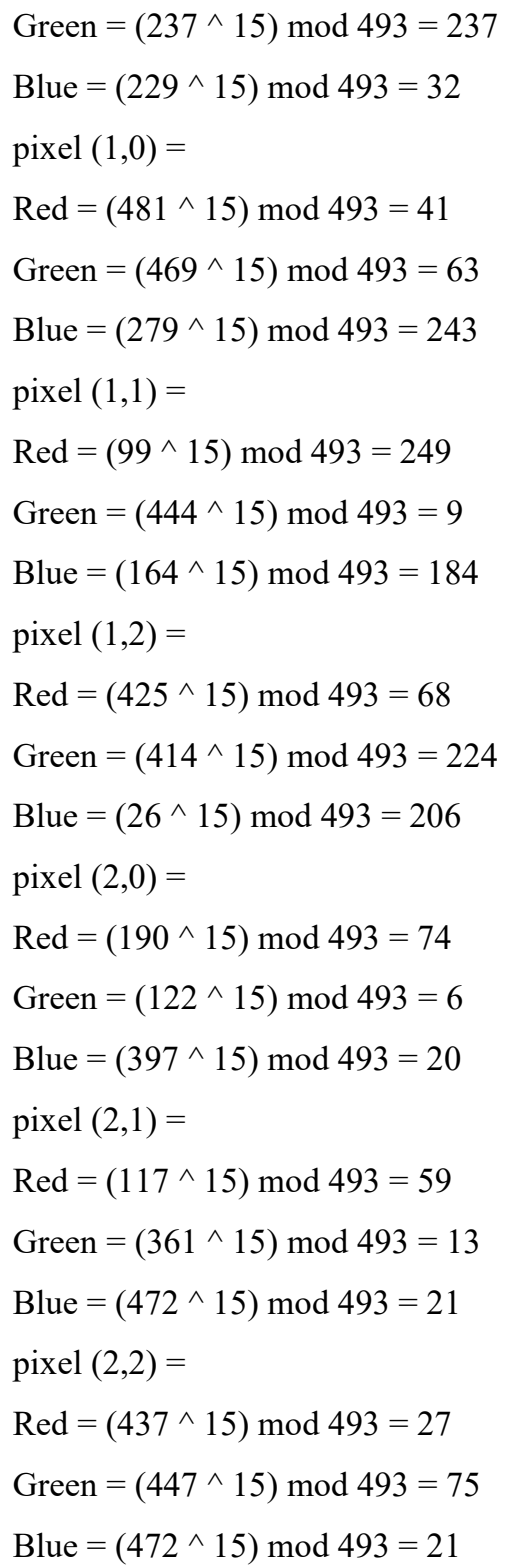

\subsection{Perhitungan Dekripsi Citra Algoritma OTP}

Selanjutnya mendekripsikan dengan algoritma RSA-CRT dengan melakukan perhitungan dengan rumus sebagai berikut :

$\mathbf{P i}=\mathbf{C i}^{\mathrm{D}} \bmod \mathbf{N}$

Maka proses dekripsi citra dengan algoritma RSA-CRT Sebagai Berikut :

Kunci Private yaitu

$: \mathrm{D}=15 \mathrm{~N}=493$

Kunci $=\mathrm{nH} 3 \mathrm{c} 8$

pixel $(0,0)=$

$\operatorname{Red}=(109-110) \operatorname{Mod} 256=255$

Green $=(56-72) \operatorname{Mod} 256=240$ 
Blue $=(253-51) \operatorname{Mod} 256=202$

pixel $(0,1)=$

$\operatorname{Red}=(75-99) \operatorname{Mod} 256=232$

Green $=(0-56) \operatorname{Mod} 256=200$

Blue $=(16-110) \operatorname{Mod} 256=162$

pixel $(0,2)=$

$\operatorname{Red}=(64-72) \operatorname{Mod} 256=248$

Green $=(237-51) \operatorname{Mod} 256=186$

Blue $=(32-99) \operatorname{Mod} 256=189$

pixel $(1,0)=$

$\operatorname{Red}=(41-56) \operatorname{Mod} 256=241$

Green $=(63-110) \operatorname{Mod} 256=209$

Blue $=(243-72) \operatorname{Mod} 256=171$

pixel $(1,1)=$

$\operatorname{Red}=(249-51) \operatorname{Mod} 256=198$

Green $=(9-99) \operatorname{Mod} 256=166$

Blue $=(184-56) \operatorname{Mod} 256=128$

pixel $(1,2)=$

$\operatorname{Red}=(68-110) \operatorname{Mod} 256=214$

Green $=(224-72) \operatorname{Mod} 256=152$

Blue $=(206-51) \operatorname{Mod} 256=155$

pixel $(2,0)=$

$\operatorname{Red}=(74-99) \operatorname{Mod} 256=231$

Green $=(6-56) \operatorname{Mod} 256=206$

Blue $=(20-110) \operatorname{Mod} 256=166$

pixel $(2,1)=$

$\operatorname{Red}=(59-72) \operatorname{Mod} 256=243$

Green $=(13-51) \operatorname{Mod} 256=218$

Blue $=(21-99) \operatorname{Mod} 256=178$

pixel $(2,2)=$

Red $=(27-56) \operatorname{Mod} 256=227$

Green $=(75-110) \operatorname{Mod} 256=221$

Blue $=(21-72) \operatorname{Mod} 256=205$

\section{KESIMPULAN}

Berdasarkan hasil perancangan dan pembuatan program aplikasi kriptografi menggunakan metode OTPdan RSA-CRTini dapat di ambil kesimpulan sebagai berikut :

1. Aplikasi pengamanan citramenggunakan algoritma OTP dan RSA-CRT mempunyai dua teknik pembacaan yaitu teknik enkripsi mengubah file asli menjadi file yang tidak dapat dibaca dan teknik dekripsi mengubah file yang tidak dapat dibaca menjadi fileasli.

2. Aplikasi pengamanan mempunyai kalmiat sandi atau passphare yang harus diingat dan bersifat sensitif, maksudnya huruf besar dan kecil dibedakan,agar passphare sulit ditebak oleh siapapun. 
3. Pengamanan citra dengan menggunakan algoritma OTP dan RSA-CRT untuk merahasiakan citra berjalan dengan baik. citra berhasil di enkripsi dan di dekripsi, percobaan yang dilakukan pada algoritma OTP dan RSA-CRT waktu proses yang di hasilkan dekripsi lebih cepat dibandingkan hasil enkripsi.

\section{REFERENSI}

[1] D. R. I. M. Setiadi, E. H. Rachmawanto, and C. A. Sari, "Implementasi One Time Pad Kriptografi Pada Gambar Grayscale Dan Gambar Berwarna," Pros. Semin. Nas. Multi Disiplin Ilmu Call Pap. Unisbank Ke-3(Sendi_U 3), pp. 50-56, 2017.

[2] R. Herteno, "Steganografi Untuk Pesan Terenskripsi Menggunakan Agoritma," 2019.

[3] N. R. Nasution, "Kombinasi RSA-CRT dengan Random LSB untuk Keamanan Data,” vol. 5341, no. April, pp. 32-42, 2017.

[4] A. P. N. Nurdin, “Analisa Dan Implementasi Kriptografi Pada Pesan Rahasia,” Jesik, vol. 3, no. 1, pp. 1-11, 2017, [Online]. Available: nnurdin69@gmail.com.

[5] A. Fauzi, Y. Maulita, and Novriyenni, "Perancangan Aplikasi Keamanan Pesan Menggunakan Algoritma Elgamal Denganmemanfaatkan Algoritma One Time Pad Sebagai Pembangkit Kunci,” J. Tek. Inform. Kaputana, vol. 1, no. 1, pp. 1-9, 2017.

[6] D. Garg and S. Verma, "Improvement over public key cryptographic algorithm," 2009 IEEE Int. Adv. Comput. Conf. IACC 2009, pp. 734-739, 2009, doi: 10.1109/IADCC.2009.4809104.

\section{BIBLIOGRAFI PENULIS}

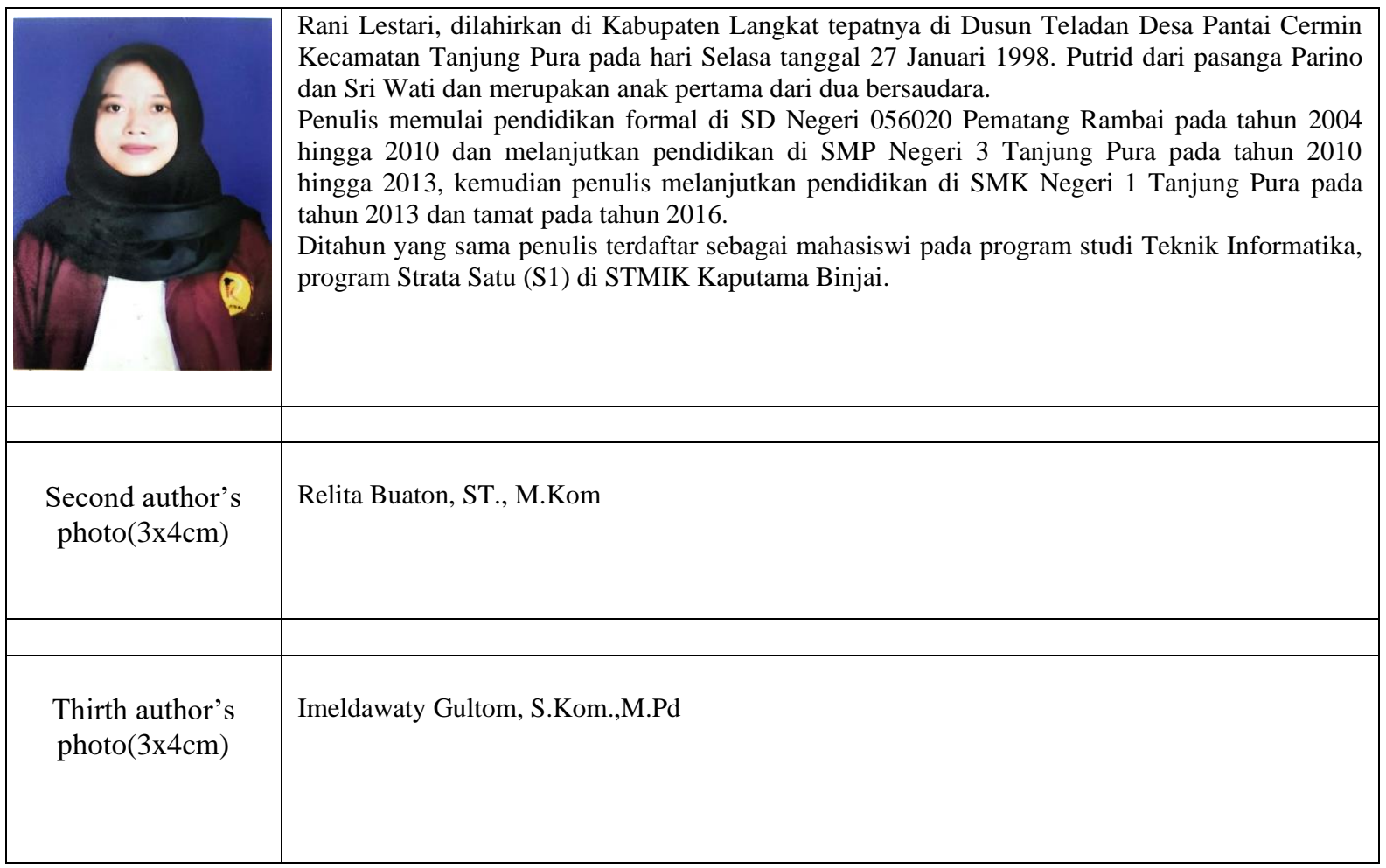

